\title{
Cooperative Mobile Learning for the Investigation of Natural Science Courses in Elementary Schools
}

\author{
Po-Sen Huang ${ }^{1,2}$, Po-Sheng Chiu ${ }^{3, * \mathbb{C}}$, Yueh-Min Huang ${ }^{1}$, Hua-Xu Zhong ${ }^{1}$ and Chin-Feng Lai ${ }^{1}$ \\ 1 Department of Engineering Science, National Cheng Kung University, Tainan City 701, Taiwan; \\ phuang@tajen.edu.tw (P.-S.H.); huang@mail.ncku.edu.tw (Y.-M.H.); \\ k43122003@gmail.com (H.-X.Z.); cinfon@ieee.org (C.-F.L.) \\ 2 Department of Nursing, Tajen University, Pingtung County 907, Taiwan \\ 3 Department of E-learning Design and Management, National Chiayi University, Chiayi County 621, Taiwan \\ * Correspondence: chiups@mail.ncyu.edu.tw; Tel.: +886-52263411 (ext. 1531)
}

Received: 2 July 2020; Accepted: 6 August 2020; Published: 14 August 2020

check for updates

\begin{abstract}
The rapid development of technologies such as tablet PCs and 4G/5G networks has further enhanced the benefits of mobile learning. Although mobile devices are convenient and provide a variety of learning benefits, they are unable to improve students' learning outcomes without an appropriate learning strategy. Furthermore, little research has been conducted to examine the effects of using collaborative learning on mobile devices. This study proposed a cooperative learning framework using Google Docs to explore the learning outcomes of students of natural science in an elementary curriculum. The study was of a quasi-experimental design with an experimental group (cooperative learning) and a control group (personal learning). The results show that a cooperative learning approach using Google Docs improved learning outcomes, teaching interest, and understanding of campus plants, and reduced cognitive load. One conclusion of the study is that the collaborative learning approach associated with mobile learning is more effective than personal learning. In addition, this paper also provides brief recommendations to expand on the study's limitations. Future work should investigate the impact of collaborative learning on different environments for mobile learning.
\end{abstract}

Keywords: cooperative learning; mobile learning; learning effects; cognitive load; learning satisfaction

\section{Introduction}

The rapid development of tablet PCs and 4G/5G network technology has further enhanced the benefits of mobile learning. Numerous studies have explored learning effects of mobile and ubiquitous learning in e-learning environments [1-6]. The research of Hwang and Tsai [7] demonstrated learning benefits of implementing mobile learning in classrooms, including more active learning and better learning outcomes for students.

However, most studies of mobile learning have focused on personal learning, whereas few studies have investigated explicitly cooperative learning activities using tablet PCs as learning devices in a mobile learning environment, for example, Dorouka, Papadakis, and Kalogiannakis [8] studies the use of tablets and apps to cultivate early childhood interest and learning in STEM (science, technology, engineering, and math) education. Chou and Feng [9] examined the use of tablet computers to improve high school students' engineering knowledge through different engineering activities. In addition, some studies have integrated collaborative learning with mobile learning [10-12]. The combination of mobile learning with collaborative learning methods requires further investigation of the learning effects and the design approach. 
Therefore, the current study used a cooperative learning strategy to increase the effects of mobile learning through group interaction with peers and thus further enhance students' learning achievement and motivation in a mobile learning environment. The cooperative approach was used in a natural science course of an elementary school as the learning activity, and the learning environment was a plant garden in the elementary school. In the cooperative learning process, the students may be dispersed in their observation of different kinds of plants. As a result, they are unable to directly communicate or immediately discuss their findings with each other, thus weakening the effect of the cooperative learning approach. To overcome this problem, Google Docs was used as a cooperative learning platform in which students are able to hold discussions with each other using instant communication. Furthermore, the learning platform allows instructors to understand and control the learning situation of each student. To evaluate the effectiveness of the cooperative learning approach, pre- and post-tests were conducted as the analysis tools to evaluate the effectiveness of learning. Thus, this study explored the learning process of students and compared the learning achievements of cooperative learning and individual learning. Finally, a questionnaire and interview were used to understand the applicability of the cooperative learning approach and the satisfaction of students in natural science courses.

In this study, the cooperative learning approach was used to conduct a mobile learning activity. The purposes of the study were as follows:

1. What are the learning effects of using a cooperative learning approach for gaining plant knowledge on campus?

2. What is the cognitive load of using a cooperative learning approach for gaining plant knowledge on campus?

3. What is the degree of learning satisfaction, interest, and technology acceptance using a cooperative learning approach for gaining plant knowledge on campus?

4. What is the learning behavior associated with using a cooperative learning approach for gaining plant knowledge on campus?

\section{Literature Review}

\subsection{Mobile Learning}

Mobile learning is generally defined as "the use of mobile technology to promote learning" [7]. Based on the concept of computer-assisted learning, e-learning has developed the models of mobile and ubiquitous learning [13-15]. Mobile learning not only has the characteristics of digital information but also provides the mobility of learning [16-18]. Moreover, the mobile learning environment is more convenient than that of e-learning because students can learn at any time and in any location.

Many studies have explored the advantages of mobile learning and noted that mobile devices applied to teaching activities can effectively increase learning motivation and improve learning performance [19-21]. In particular, the research of Kalogiannakis and Papadakis [22] suggests the need for mobile learning, rather than the use of technology, to teach student-centered pedagogical learning. These mobile learning models can be used to accomplish the target of personalized learning and thus allow students to obtain good learning outcomes by considering their individual learning progress and status.

\subsection{A Situational Learning Environment in Mobile Learning}

Situational learning emphasizes that learning occurs in a real situation, and the acquisition of knowledge is achieved through interaction with the situation. The characteristics of contextual learning allow learners to achieve effective results in a meaningful learning environment. However, previous research has noted that mobile learning activities in natural science courses without appropriate learning strategies and tools may result in disappointing student learning outcomes. Students must deal with both the natural sciences and digital learning environment simultaneously; this learning process may be too complex, thus affecting their learning $[1,6,20-23]$. For these reasons, the most 
important issue is how to combine real situations and digital learning resources in an action learning environment to achieve the best learning outcomes.

Although students have used mobile devices in learning activities, it was found to be necessary to construct reliable activities in real situations $[14,23,24]$. The abstract knowledge of general teaching without the support of a real situation is called inert knowledge, which is a challenge for the human brain to migrate and transform. Several studies have noted that teaching in a learning environment of real-life situations can help students understand learning objects and further enhance their knowledge $[4,6,13,15]$. Some researchers used mobile devices and wireless communication technologies as assisted-learning tools so that students could develop relative knowledge with the interaction of a mobile learning (m-learning) system in a real environment $[2,6,15,21]$. In addition, studies have also found that the use of mobile devices in a situational learning environment led to improvements in students' English writing skills [15,25].

\subsection{A Cooperative Learning Approach}

Cooperative learning is defined as an active learning format that involves working together as a group, and the use of small groups to improve own learning and that of other group members [26,27]. Several studies have identified students involved in collaborative learning processes through group discussions, peer support, and guidance, emphasizing individual responsibility and mutual interdependence of team members [12,28,29]. Cooperative learning is more efficient in an interactive atmosphere that encourages learning discipline, problem-solving, learning motivation, a positive attitude [12,21], and critical thinking skills [30], and has become a widely used teaching strategy.

\section{Methods}

\subsection{A Cooperative Learning Approach in Mobile Learning System}

In this study, we used the cooperative learning approach in an elementary school to observe and understand the knowledge of natural science. The main feature of cooperative learning is that group members cooperate with each other and mutually complete jobs by sharing information relevant to learning tasks to achieve the learning targets or objects. The cooperative learning process had the following elements: (1) Firstly, a heterogeneous group consisted of students of different achievements, and the number of students in a group ranged from three to six. (2) The teacher was responsible for the assignment of a learning worksheet. (3) The members of each group commonly practiced the tasks of the learning worksheets with the teacher. (4) Students with similar ability in each group were gathered at the same table in the homogeneous grouping method. (5) A competition was held. This cooperative learning framework is shown in Figure 1.

This study used Google Docs and Google++ social networking sites to help students construct, exchange, and organize knowledge, as shown in Figure 1. The Google Docs social networking site is an information exchanging site and learning platform on which users can talk with their friends, receive information relating to any topics from their friends or other sites, be classified into social groups through the categorization and integration of "Hangouts", and select messages based on the category of the social circles. Kutluk and Gülmez [23] noted that Google Docs and Google++ social networking sites can improve cooperative learning through the function of social circles and help students organize knowledge and learning experiences. Google++ differs from other social networking sites that provide complex information because the web interface of Google Docs is simple and consistent. Google Docs has two major advantages in comparison to OneNote and other social networking sites. First, users can more easily access and share the information on Google Docs. Second, Google Docs has excellent version control, with only one version of a document easily being able to be revised and expanded by all learners. 


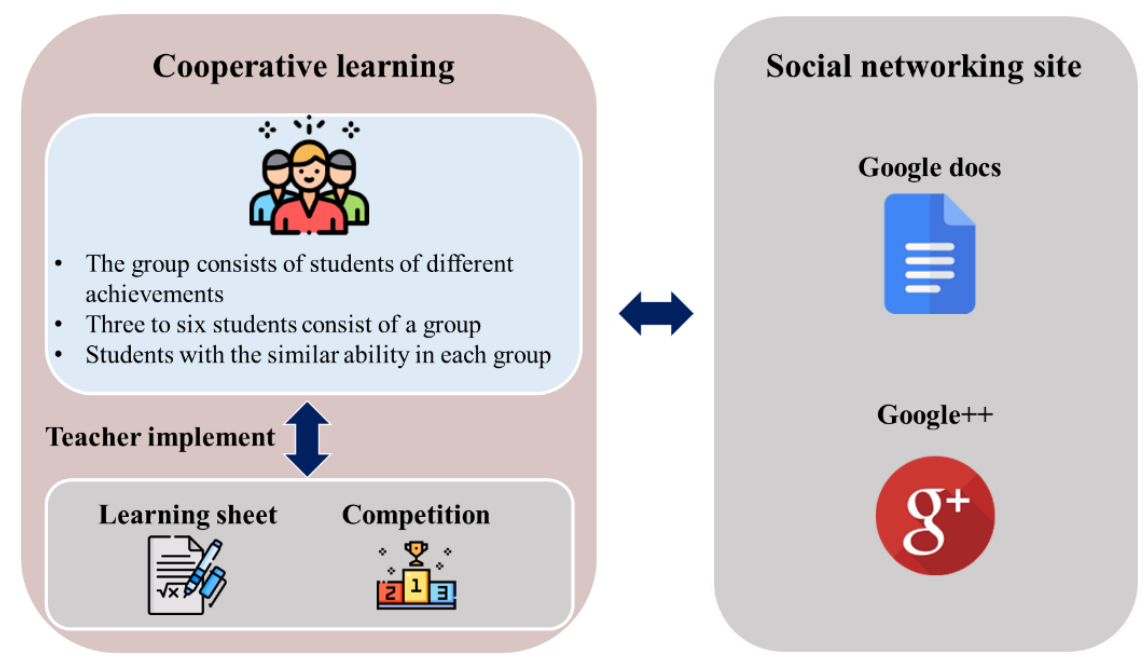

Figure 1. Cooperative learning framework.

In addition, Google Docs is simpler than Facebook, which has many complex messages in its applications and advertisements, thereby interfering with learning and increasing the cognitive load. Moreover, the account application of Google Docs is more straightforward than that of Facebook; thus, some researchers believe that Google Docs is more suitable as a learning platform than Facebook. Therefore, this study used the Google Docs and Google++ social networking learning platform to help students interpret and organize their personal knowledge.

\subsection{Participants}

Sixty sixth-grade students of Hong WaCuo elementary school in Tainan City participated in this experiment. To confirm their prior knowledge of the natural science course, students completed a preliminary test. At the beginning of the learning activity, the students were randomly divided into an experimental group and a control group, with 30 students each. Students of the experimental group used the cooperative learning approach, whereas students of the control group used the conventional individual learning approach.

\subsection{Experimental Procedure}

The learning environment of this experiment was a plant garden in the Hong WaCuo elementary school. The plants of the plant garden included "Spindlepalm", "Golden dewdrop", "Variegated leaf croton", "Golden Leaves", “Star Cluster", "Bread-fruit Tree", "Liquidambar", "Common garcinia", "Golden Bamboo", "Odour-bark cinnamon", "Blue sky vine", and "Devil's lvy". The experimental procedure and students were randomly allocated to two groups to compare the different learning approaches, and the duration of the experimental process was approximately two hours. Prior to the learning activity, a preliminary test (pre-test) was conducted to evaluate the prior plant knowledge of the two groups. The experimental procedure is shown in Figure 2.

The experimental and control groups observed the characteristics of plants using tablet PCs. During the learning activity, students of the experimental group participated in the learning activity using the cooperative learning approach. The students observed the plants and used Google Docs to share their photos and discuss answers to the learning questions. After observing the plants, cooperative learning was conducted to increase students' learning motivation. The experimental group used Google Docs to have discussions during the learning process. By comparison, students of the control group used conventional individual learning. Students used a tablet PC to observe the plants and answer the learning questions. After this learning activity, students prepared to take a post-test to evaluate their understanding of plant knowledge. The students had to answer questions related to plant knowledge based only on what they had memorized. During the post-test, students 
were monitored to ensure there was no cheating. At the end of the experiment, questionnaires and interviews were used to evaluate students' attitudes towards the learning activity.

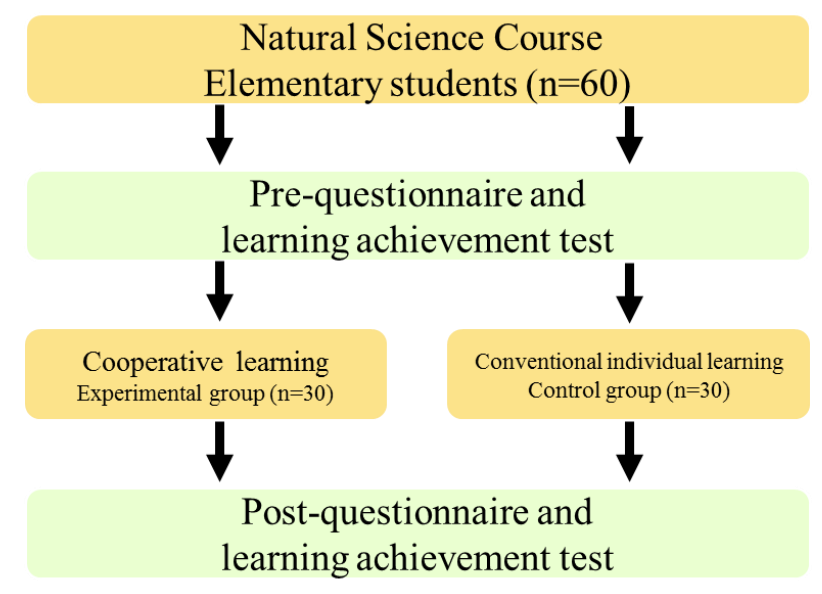

Figure 2. Experimental procedure.

\subsection{Measuring Tools}

The pre- and post-tests were based on data from the Taiwan encyclopedia and developed by professional instructors. The pre-test was used to evaluate the basic plant knowledge of learners, and included 20 single answer questions for a total test score of 100 . The post-test was used to examine participants' plant knowledge following their observations of the plants on the campus, and contained 17 questions consisting of 14 single answer questions and three short answer questions, giving a maximum overall test score of 100 .

The learning satisfaction questionnaire was examined by two domain experts, who approved its validity. The English version of the questionnaire used in this study was translated from the Chinese. This questionnaire identified four dimensions as follows: (1) learning satisfaction; (2) learning interests; (3) perceived ease of use; (4) perceived usefulness. The first dimension included four items, and the goal was to collect information about the students' learning satisfaction in the cooperative learning approach. The second dimension of the questionnaire also included four items and aimed to explore the students' perceived ease of use of the proposed cooperative learning platform. The third dimension of the questionnaire included four items and aimed to explore the students' perceived usefulness of the proposed cooperative learning platform. The fourth dimension of the questionnaire contained four items and aimed to explore the students' learning during the proposed learning approach. Each question was rated on a seven-point Likert scale (strongly agree, agree, weak agree, neutral, weak disagree, disagree, and strongly disagree). The reliability of the questionnaire was analyzed with SPSS software. Cronbach's $\alpha$ is a measure of internal consistency for each dimension of a questionnaire. A Cronbach's $\alpha$ value higher than 0.7 indicates high reliability. The Cronbach's $\alpha$ values of the four dimensions in the questionnaire used in the study were $0.80,0.72,0.75$, and 0.79 .

Moreover, a cognitive load questionnaire [31,32] was applied to evaluate the cognitive load level of the students in the two groups. The cognitive load questionnaire included two factors, namely mental load and mental effort, to investigate the difference in cognitive load for the two learning approaches. The mental effort factor shows whether the instructional design increased extraneous cognitive load and germane cognitive load. Mental load evaluated the intrinsic cognitive load related to the difficulty of the material. Each factor had two questions that were rated on a seven-point scale, and the total score of each factor was 14. The Cronbach's $\alpha$ value of the cognitive load questionnaire was 0.76 , indicating a high degree of reliability. 


\section{Results}

\subsection{Learning Achievement}

Before the learning activity, the students completed a pre-test to evaluate their basic knowledge of plants. Table 1 shows the means and standard deviations of the pre-test for the experimental and control groups. The results reveal that the mean of the experimental group $(\mathrm{M}=43.16, \mathrm{SD}=8.55)$ was approximately equal to that of the control group $(\mathrm{M}=46.50, \mathrm{SD}=12.04)$. In addition, $t$-test analysis was conducted to determine whether the means of the two groups were significantly different. For the $t$-test analysis of the pre-test, there was no significant difference between the two groups $(t=1.24$, $p>0.05)$.

Table 1. The $t$-test result of pre-test.

\begin{tabular}{cccccc}
\hline Variable & Group & N & Mean & SD & $t$ \\
\hline \multirow{2}{*}{ Pre-test } & Experimental & 30 & 43.16 & 8.55 & 1.24 \\
& Control & 30 & 46.50 & 12.04 & \\
\hline
\end{tabular}

To determine the effects of using a cooperative learning approach for learning about the plants of the campus, Table 2 shows the means and standard deviations of the post-test. The experimental group $(\mathrm{M}=75.83, \mathrm{SD}=13.86)$ in the post-test showed a better learning achievement than the control group $(\mathrm{M}=63.16, \mathrm{SD}=15.59)$. The $t$-test analysis showed results that were significantly different $(t=-3.32$, $p<0.05)$. The results of the post-test indicate that the experimental group using the cooperative learning approach performed significantly better than the control group using individual learning.

Table 2. The $t$-test results of post-test.

\begin{tabular}{cccccc}
\hline Variable & Group & N & Mean & SD & $t$ \\
\hline \multirow{2}{*}{ Post-test } & Experimental & 30 & 75.83 & 13.86 & $-3.32{ }^{*}$ \\
& Control & 30 & 63.16 & 15.59 & \\
\hline \multicolumn{5}{c}{ Note: $*<0.05$, SD: standard deviation. }
\end{tabular}

\subsubsection{The Learning Outcomes of Students of Different Learning Achievement Groups}

In this section, we investigate the learning achievements of students in the experimental group, who used cooperative learning for gaining knowledge about plants, to determine if their learning outcomes were significantly different. The students of the experimental group were divided into three groups, and the 10 students achieving the highest $33.3 \%$ of scores in the pre-test were considered a high-learning-achievement group; the 10 students who achieved the lowest $33.3 \%$ of scores in the pre-test were regarded as a low-learning-achievement group; and the remaining 10 students were considered a medium-learning-achievement group. The difference between pre- and post-test results were analyzed for the students of the high-learning-achievement group, as shown in Table 3. The results of the post-test $(M=64.5, S D=13.83)$ outperformed those of the pre-test $(M=59, S D=6.14)$. The results of the $t$-test analysis show no significant difference $(t=-1.27, p>0.05)$.

Table 3. The $t$-test results of pre- and post-test for the students of the high-learning-achievement group.

\begin{tabular}{cccccc}
\hline Variable & Group & N & Mean & SD & $t$ \\
\hline High & Pre-test & 10 & 59 & 6.14 & -1.27 \\
achievement & Post-test & 10 & 64.5 & 13.83 & \\
\hline
\end{tabular}

Note: SD: standard deviation. 
Table 4 shows the means and standard deviations of pre- and post-tests for the students of the medium-learning-achievement group. The results indicate that the results of the post-test $(M=64$, $\mathrm{SD}=13.70)$ were higher than those of the pre-test $(\mathrm{M}=47.5, \mathrm{SD}=3.53)$. The results of the $t$-test analysis show that this difference was significant $(t=-3.91, p<0.01)$.

Table 4. The $t$-test results of pre- and post-test for the students of the medium-learning-achievement group.

\begin{tabular}{cccccc}
\hline Variable & Group & N & Mean & SD & $t$ \\
\hline Medium & Pre-test & 10 & 47.5 & 3.53 & $-3.91^{* *}$ \\
achievement & Post-test & 10 & 64 & 13.70 & \\
\hline \multicolumn{5}{c}{ Note: ${ }^{* *} p<0.01$; SD: standard deviation. }
\end{tabular}

The means and standard deviations of pre- and post-tests for the students of the low-learningachievement groups are shown in Table 5. The results of the post-test $(M=61, S D=15.23)$ were higher than those of the pre-test $(M=33, S D=6.32)$. The results of the $t$-test analysis show that the difference was significant $(t=-5.85, p<0.01)$.

Table 5. The $t$-test results of pre- and post-test for the students of the low-learning-achievement group.

\begin{tabular}{cccccc}
\hline Variable & Group & N & Mean & SD & $t$ \\
\hline Low & Pre-test & 10 & 33 & 69.32 & $-5.85^{* *}$ \\
achievement & Post-test & 10 & 61 & 15.23 & \\
\hline
\end{tabular}

Note: ${ }^{* *} p<0.01$; SD: standard deviation.

\subsubsection{The Relationship of Learning Achievement among Three Groups}

The relationship between the results of the post-test and the progressive rate for the students of different learning achievements is shown in Table 6. The results indicate that the results of the post-test of the high-achievement group $(\mathrm{M}=64.5, \mathrm{SD}=15.23)$ were higher than those of medium $(\mathrm{M}=64, \mathrm{SD}=13.70)$ and low-achievement groups $(\mathrm{M}=61, \mathrm{SD}=13.83)$. However, the results of the analysis of variance (ANOVA) analysis show that there was no significant difference in the results of the post-test for the students of the three groups $(F=0.17, p>0.05)$. In contrast, the ANOVA analysis showed there was a significant difference in the progressive rate of learning outcomes $(F=6.4$, $p<0.01)$, and the results of the low-learning-achievement group $(\mathrm{M}=28, \mathrm{SD}=15.12)$ were significantly higher than those of both the medium-learning-achievement group $(\mathrm{M}=16.5, \mathrm{SD}=13.34)$ and the high-learning-achievement group $(\mathrm{M}=5.5, \mathrm{SD}=13.63)$.

Table 6. ANOVA analysis results of the post-test and progressive rate for the students of different learning achievement groups.

\begin{tabular}{ccccccc}
\hline Variable & Group & N & Mean & SD & $\boldsymbol{F}$ & Pairwise Comparisons \\
\hline \multirow{3}{*}{ Post-test } & Low & 10 & 61 & 13.83 & 0.17 & \\
& Medium & 10 & 64 & 13.70 & & \\
& High & 10 & 64.5 & 15.23 & & \\
Progressive rate & Low & 10 & 28 & 15.12 & $6.4^{* *}$ & (Low $>$ High) ** \\
& Medium & 10 & 16.5 & 13.34 & & \\
& High & 10 & 5.5 & 13.63 & \\
\hline
\end{tabular}

\subsection{Cognitive Load}

To further investigate the reason for the differences in the learning achievements of the students of the experimental group, and whether the cooperative learning approach affected the learning process of students, the cognitive load questionnaire was used to evaluate the cognitive load level for this learning activity. Table 7 indicates that the mental load and mental effect of the experimental group 
were lower than those of the control group. In addition, $t$-test analysis indicated a significant difference for the mental load $(t=-2.60$ and $p<0.05)$ and mental effect $(t=-2.03, p<0.05)$.

Table 7. The $t$-test result of the cognitive load levels of the experimental group.

\begin{tabular}{cccccc}
\hline Variable & Group & N & Mean & SD & $t$ \\
\hline \multirow{2}{*}{ Mental load } & Experimental & 30 & 5.30 & 3.39 & $-2.60 *$ \\
& Control & 30 & 6.96 & 1.92 & \\
Mental effect & Experimental & 30 & 5.93 & 3.64 & -2.03 * \\
& Control & 30 & 7.10 & 1.84 & \\
\hline
\end{tabular}

Note: ${ }^{*} p<0.05 ;$ SD: standard deviation.

Moreover, the results of the ANOVA analysis of the cognitive load levels for the students of different learning achievement groups are shown in Table 8. The results indicated there was no significant difference in mental load $(F=0.64, p>0.05)$ and mental effect $(F=0.60, p>0.05)$ for the students of the three groups. The mental load of the high-achievement group $(\mathrm{M}=4.3, \mathrm{SD}=2.31)$ were lower than that of the medium $(\mathrm{M}=5.9, \mathrm{SD}=4.17)$ and low-achievement groups $(\mathrm{M}=5.7, \mathrm{SD}=3.56)$. Furthermore, the mental effect of the high-achievement group $(\mathrm{M}=5.1, \mathrm{SD}=2.68)$ was lower than that of the medium $(\mathrm{M}=5.8, \mathrm{SD}=3.85)$ and low-achievement groups $(\mathrm{M}=6.9, \mathrm{SD}=4.35)$.

Table 8. ANOVA analysis results of cognitive load levels for the students of different learning achievement groups.

\begin{tabular}{ccccccc}
\hline Variable & Group & N & Mean & SD & F & Pairwise Comparisons \\
\hline \multirow{3}{*}{ Mental load } & Low & 10 & 5.7 & 3.56 & 0.64 & \\
& Medium & 10 & 5.9 & 4.17 & & \\
& High & 10 & 4.3 & 2.31 & & \\
\multirow{2}{*}{ Mental effect } & Low & 10 & 6.9 & 4.35 & 0.60 & \\
& Medium & 10 & 5.8 & 3.85 & & \\
& High & 10 & 5.1 & 2.68 & & \\
\hline
\end{tabular}

\subsection{Learning Satisfaction}

Table 9 shows the mean and standard deviation of the learning satisfaction dimension for the experimental group; the results indicate an average rating of 5.9 and a standard deviation of 1.27. Students in the experimental group had a high degree of learning satisfaction in the cooperative learning approach, and they were satisfied with the cooperative learning approach, which provided information that allowed them to understand easily $(\mathrm{M}=6.03$ and $\mathrm{SD}=1.21)$. Moreover, most of the students recognized that the cooperative learning approach helped them learn the necessary knowledge $(\mathrm{M}=5.73$ and $\mathrm{SD}=1.33)$. In addition, students would recommend the cooperative learning approach to other learners $(\mathrm{M}=5.97$ and $\mathrm{SD}=1.37)$.

Table 9. Analysis of the students' learning satisfaction in the proposed approach.

\begin{tabular}{lcc}
\hline \multicolumn{1}{c}{ Questionnaire Items } & Mean & SD \\
\hline 1. I was satisfied at the cooperative learning approach to help me learn the necessary knowledge. & 5.73 & 1.33 \\
2. I was satisfied at the cooperative learning approach which provides information to facilitate & 6.03 & 1.21 \\
me to understand easily. & 5.87 & 1.19 \\
3. I was satisfied at the cooperative learning approach which meets my learning needs. & 5.97 & 1.37 \\
4. I would like to recommend the cooperative learning approach to other learners. & \\
\hline
\end{tabular}

\subsection{Usage Intention}

Results from the usage intention dimension of the questionnaire for the experimental group are shown in Table 10 and indicate an average rating of 5.6 and a standard deviation of 1.51. Furthermore, 
students of the experimental group indicated they would like to use the cooperative learning approach $(\mathrm{M}=5.87$ and $\mathrm{SD}=1.50)$. The results show that they intended to increase the use of the cooperative learning approach $(\mathrm{M}=5.37$ and $\mathrm{SD}=1.58)$ and most of the students stated that they would continue to use the cooperative learning approach in the future $(\mathrm{M}=5.50$ and $\mathrm{SD}=1.50)$.

Table 10. Analysis of the students' usage intentions in using the proposed approach.

\begin{tabular}{lcc}
\hline \multicolumn{1}{c}{ Questionnaire Items } & Mean & SD \\
\hline 1. I would like to use the cooperative learning approach. & 5.87 & 1.50 \\
2. I am pleased to use the cooperative learning approach. & 5.67 & 1.47 \\
3. I tend to increase the use of the cooperative learning approach. & 5.37 & 1.58 \\
4. I think that I can continue to use the cooperative learning approach in the future. & 5.50 & 1.50 \\
\hline
\end{tabular}

\subsection{The Perceived Ease of Use and Perceived Usefulness}

Table 11 shows the means and standard deviations of the perceived ease of use and perceived usefulness of the proposed learning platform. The results show that students of the experimental group agreed that the proposed learning platform was easy to use and useful, with an average rating of 5.85 and a standard deviation of 1.14. In addition, its ease of use was demonstrated by the items "It is easy for me to learn how to use the designed interface of the learning platform" $(\mathrm{M}=5.70$ and $\mathrm{SD}=1.29)$, and "It is easy for me to operate the proposed learning platform" $(\mathrm{M}=5.77$ and $\mathrm{SD}=1.10)$. Students considered that the proposed learning platform was very useful for them $(\mathrm{M}=5.8$ and $\mathrm{SD}=1.09)$ and indicated that they were very interested in the presented information of the proposed learning platform $(\mathrm{M}=6.13$ and $\mathrm{SD}=1.10)$.

Table 11. Analysis of the perceived ease of use and perceived usefulness in using the proposed learning platform.

\begin{tabular}{lcc}
\hline \multicolumn{1}{c}{ Questionnaire Items } & Mean & SD \\
\hline 1. It is easy for me to learn how to use the designed interface of learning platform. & 5.70 & 1.29 \\
2. It is easy for me to operate the proposed learning platform. & 5.77 & 1.10 \\
3. It is very clear and easy to understand for me about using the proposed learning platform. & 5.87 & 1.12 \\
4. I feel the functions of the proposed learning platform are very to use. & 5.83 & 1.14 \\
5. I think this proposed learning platform is very useful for me. & 5.80 & 1.09 \\
6. I was very interested in the presented information of proposed learning platform. & 6.13 & 1.10 \\
\hline
\end{tabular}

\subsection{Interview Results}

To further explore the learning satisfaction of students in this learning activity, the instructor randomly selected five students of the control group to assess their learning attitude. They indicated they needed to move to many places to observe ten kinds of plants and answer ten questions about plant knowledge by themselves. However, this was difficult for the students because the learning task was too demanding. Due to the time limit of the experiment, students were unable to complete all learning tasks, resulting in lower post-test scores. In addition, the instructor interviewed four students of the three different learning achievement groups separately in the experiment group. The results of the interview are shown in Table 12. 
Table 12. Interview results of students in the experiment.

\begin{tabular}{|c|c|}
\hline Different Groups & Interview Results \\
\hline Experimental group & $\begin{array}{l}\text { High-achievement group: } \\
\text { This learning activity is very interesting, and Tablet PC can help me take picture into plants } \\
\text { and upload the photos of plants to share with my partners on Google++. Meanwhile, I can } \\
\text { use Google Doc to communicate with each other when we are distributing in different places. } \\
\text { This learning is very special and funny for me. } \\
\text { Medium-achievement group: } \\
\text { I consider this learning approach is very useful for me. Everyone only observes 1/3 part of } \\
\text { plants through cooperative learning, and it reduces my burden. We can discuss the best } \\
\text { solution with each other to answer the question. For this reason, I confirm the benefits of } \\
\text { this learning approach. } \\
\text { Low-achievement group: } \\
\text { In this learning activity, I feel unpressured because my partners of high learning } \\
\text { achievement can teach me how to observe the plants and help us solve the more difficult } \\
\text { learning questions in the learning process. Therefore, I like cooperative learning, and this } \\
\text { learning approach is very useful for me. }\end{array}$ \\
\hline Control group & $\begin{array}{l}\text { In this learning activity, I have to move to many places to observe ten kinds of plants and } \\
\text { answer ten questions of plant knowledge by myself. However, I think it is difficult for me } \\
\text { because the learning task is too heavy. Due to the limit of experimental time, I seem not to } \\
\text { complete all learning tasks, resulting in my scores of pro-test is lower. I hope someone can } \\
\text { share my learning tasks, and I feel very tired after this learning activity. Therefore, I don't } \\
\text { like this individual learning approach. }\end{array}$ \\
\hline
\end{tabular}

\section{Discussion}

In this study, a cooperative learning approach was proposed to enhance the effect of learning about plants. Based on the experimental results, the experimental group performed better than the control group in the post-test. The results of the t-test analysis of the post-test show that there was a statistically significant difference in the two learning approaches, indicating that the cooperative learning approach could achieve a better learning outcome than individual learning.

\subsection{Learning Effects of Using Cooperative Learning}

The standard deviation of the post-test results of experimental and control groups was higher than those of the pre-tests. The control group may have had a higher standard deviation in its results because some students were not familiar with tablet devices, which may represent a learning obstacle. In addition, the learning approach of the experimental group facilitates heterogeneous grouping, which can achieve more effective learning outcomes. Thus, students of low and high achievement levels were grouped, allowing students of the high-achievement group to teach students of other achievement levels. Moreover, students of the high-achievement group may be motivated to work harder by learning to teach students of the low-achievement group. In addition, group activities may occur due to favorability among group members because of learning problems.

The possible reason for the above results is that the mobile collaborative learning model was distributed to each team member for some tasks, and some tasks may have been completed before being shared with others. Team members actively gained plant knowledge due to the progress of the entire group via the peer pressure of healthy competition. Another possible consideration in the implementation of mobile learning activities is that it is necessary to choose student-centered pedagogy to motivate students [22]. The effectiveness of cooperative learning is superior to that of individual learning in the learning environment of a real-life situation. This may imply that collaborative learning may be an appropriate approach to implement mobile learning. In the past, teaching activities related to plant knowledge have required the development of specific mobile digital learning platforms, such as mobile learning systems, to allow students to benefit from a learning effect $[4,11,28,32,33]$. 
This study found that mobile learning implemented with an appropriate teaching strategy can achieve good learning even without using a self-designed mobile learning system.

Moreover, the relationship between the different learning groups and learning achievements was investigated in this study. The findings showed that students of lower achievements had the highest progressive rate of student learning outcomes. Thus, the cooperative learning approach can improve learning effects. This result was similar to related research $[12,16,20]$, which indicated students of low achievement increase their motivation and learning confidence.

\subsection{The Cognitive Load of Using A Cooperative Learning}

The cognitive load questionnaire showed that the cognitive load of the experimental group was lower than that of the control group. These results thus showed that participants who were able to utilize the teaching strategies could enhance learning outcomes and reduce cognitive load. Such findings are consistent with other cooperative learning [14,15,18,28], and mobile learning studies [34].

In the questionnaire analysis, the vast majority of students agreed on a collaborative learning approach and that the experiment was fun and interesting and enhanced their learning. For some students, this result related to the cognitive load perhaps because the time allowed for the operating instructions was too short and, because not every student had a tablet PC at home, their levels of familiarity with tablet PCs will differ. In addition, some students had operating problems with their tablet PCs due to network instability, which may cause learning barriers.

\subsection{The Learning Satisfaction, Interest, and Technology Acceptance of Using A Cooperative Learning}

Previous research found that mobile learning is not intended to be a complex learning process but should facilitate the learning process of students. Appropriate application development combined with mobile devices can enhance educational outcomes [12,16,20]. These results are consistent with previous studies, which indicated that mobile learning can be applied to improve students' satisfaction [34,35] and technology acceptance [35]. The experimental group used Google Docs rather than application development to simplify the learning process and thus enhance students' learning outcomes. In particular, due to the human desire for mutual support and cooperation, it is necessary to use cooperative learning to enhance students' ability to work together [36]. Cooperative learning can enhance students' learning performance and promote the development of social and friendship bonds with their peers [37]. The experimental results show the use of the competition in the mobile learning model, compared to the previous model of mobile learning, enhanced students' learning motivation and improved their learning outcomes.

\subsection{The Learning Behavior of Cooperative Learning}

In this study, using tablet PCs as a learning tool overcomes the limits of traditional screens in mobile learning and enhances their operation and reading, providing a better learning environment for students. The cooperative learning method of this study combined the Google Docs social network learning platform with a plant course at an elementary school to evaluate the effectiveness of the method. Cooperative learning and individual learning were compared in the teaching and learning environment of a real situation. The study showed that using mobile collaborative learning methods in the experimental group resulted in better learning outcomes than those of the control group.

These results are consistent with Costa et al. [11], who noted that it is appropriate to apply the collaborative learning pedagogy on mobile learning or systems. The use of effective cooperative learning tools and learning strategies can overcome traditional learning deficiencies. In this study, achievement of students in the experimental group was improved. The feedback questionnaire also indicated that most of the students who used the mobile collaborative learning method believed the method could improve their academic performance. Therefore, it was concluded that action contest collaborative learning methods can help students discuss and improve cooperation in the field of knowledge. 


\section{Limitations and Future Work}

In this study, because of time, manpower, and resource constraints, only sixth-grade student test subjects were considered. In addition, student grades in natural sciences did not take account other factors, such as sample size, scope, favorability, and computer literacy. A small sample is not sufficient to provide reliable research evidence; thus, we are unable to generalize the study conclusions, and the results of this study and inference apply only to small samples under the studied test environment.

In future research, it is recommended that the same tablet experiment is expanded in scope and direction with larger samples to consider gender, different levels of computer literacy, different levels of education, etc. In addition, subsequent research could consider other action-learning environments or outcomes to better show the benefits of the grouping method and for reference and comparison.

In particular, collaborative learning could be implemented in different environments using mobile devices. A key question is whether students experience different learning effects depending on the learning environment. Future work should investigate the impact of collaborative learning in different environments on mobile learning. Due to advancing technology, the use of electronic paper has matured. Materials have evolved from fragile glass into a more resilient plastic; color can be displayed, rather than only black and white; and the technology of e-book readers better replicates the effects of paper than tablet PCs. Thus, electronic paper devices may be more suitable for this type of teaching experiment and could be taken into account in future studies.

\section{Conclusions and Suggestions}

This study proposed a new and effective pedagogical approach, which used a collaborative teaching framework for mobile learning to improve elementary school students' academic achievement, satisfaction, and interest, and reduce cognitive load. There are two significant practical implications of our findings. First, the findings of this study reveal that teachers can promote students' effective learning when implementing mobile learning systems through appropriate instructional strategies (e.g., cooperative learning). Second, the results of this study reveal that providing appropriate competition and other instructional strategies can increase peer engagement in learning activities and encourage working together in cooperative learning. Therefore, this study suggests that teachers should focus on instructional design and quality rather than the use of technology to maximize students' learning benefits. Moreover, teachers can use appropriate competitive strategies to integrate collaborative learning; appropriate competition can support learning outcomes, and help students discuss and improve their knowledge through collaboration.

This study provides several suggestions that aim to improve mobile learning research and education. First, instructions should be explicitly designed to improve the quality of teachers' teaching. Depending on the content, appropriate instructional strategies may be provided (e.g., competition, collaboration, challenging tasks), and different instructional strategies can be combined to generate different learning benefits for students. Second, it is important to pay attention to students' use of social networking sites and software. To provide students with learning assistance through the use of social networking sites, teachers need to know how students perceive and use them. Furthermore, it is important to understand students' learning behaviors and their learning desires. Finally, teachers should be provided with a framework or learning system to facilitate mobile learning for students. This teaching framework needs to be complete and practical for teachers. In addition, the system needs to be a mobile learning system that is flexible and easy to use, so that teachers can change subjects and thus teach more easily. These suggestions and challenges are critical. In particular, the application to other subjects (e.g., STEM or medical education) is currently an important consideration and influence on mobile learning. 
Author Contributions: Conceptualization, P.-S.H. and P.-S.C.; methodology, P.-S.C.; software, Y.-M.H.; validation, P.-S.H.; formal analysis, P.-S.C.; investigation, Y.-M.H.; resources, P.-S.C.; data curation, H.-X.Z.; writing-original draft preparation, P.-S.H.; writing—review and editing, H.-X.Z.; visualization, C.-F.L.; supervision, Y.-M.H.; project administration, Y.-M.H.; funding acquisition, C.-F.L. All authors have read and agreed to the published version of the manuscript.

Funding: This research was funded by the Ministry of Science and Technology, Taiwan, under Grant no. MOST108-2511-H-415-003-MY3.

Conflicts of Interest: The authors declare no conflict of interest.

\section{References}

1. Bernacki, M.L.; Crompton, H.; Greene, J.A. Towards convergence of mobile and psychological theories of learning. Contemp. Educ. Psychol. 2020, 60, 101828. [CrossRef]

2. Pimmer, C.; Mateescu, M.; Gröhbiel, U. Mobile and ubiquitous learning in higher education settings. A systematic review of empirical studies. Comput. Hum. Behav. 2016, 63, 490-501. [CrossRef]

3. Sarrab, M.; Elbasir, M.; Alnaeli, S. Towards a quality model of technical aspects for mobile learning services: An empirical investigation. Comput. Hum. Behav. 2016, 55, 100-112. [CrossRef]

4. So, S. Mobile instant messaging support for teaching and learning in higher education. Internet High. Educ. 2016, 31, 32-42. [CrossRef]

5. Sung, Y.-T.; Lee, H.-Y.; Yang, J.-M.; Chang, K.-E. The quality of experimental designs in mobile learning research: A systemic review and self-improvement tool. Educ. Res. Rev. 2019, 28, 100279. [CrossRef]

6. Vázquez-Cano, E. Mobile distance learning with smartphones and apps in higher education. Educ. Sci. Theory Pract. 2014, 14, 1505-1520. [CrossRef]

7. Hwang, G.J.; Tsai, C.C. Research trends in mobile and ubiquitous learning: A review of publications in selected journals from 2001 to 2010. Br. J. Educ. Technol. 2011, 42, E65-E70. [CrossRef]

8. Dorouka, P.; Papadakis, S.; Kalogiannakis, M. Tablets and apps for promoting robotics, mathematics, STEM education and literacy in early childhood education. Int. J. Mob. Learn. Organ. 2020, 14, $255-274$. [CrossRef]

9. Chou, P.-N.; Feng, S.-T. Using a tablet computer application to advance high school students' laboratory learning experiences: A focus on electrical engineering education. Sustainability 2019, 11, 381. [CrossRef]

10. Aghajani, M.; Adloo, M. The effect of online cooperative learning on students' writing skills and attitudes through telegram application. Int. J. Instr. 2018, 11, 433-448. [CrossRef]

11. Costa, R.S.; Medrano, M.M.; Ostáriz, P.L.; Moreno-Guerrero, A.-J. How to teach pre-service teachers to make a didactic program? The collaborative learning associated with mobile devices. Sustainability 2020, 12, 3755. [CrossRef]

12. Parsazadeh, N.; Ali, R.; Rezaei, M. A framework for cooperative and interactive mobile learning to improve online information evaluation skills. Comput. Educ. 2018, 120, 75-89. [CrossRef]

13. Cano, E.V. Mobile learning with Twitter to improve linguistic competence at secondary schools. New Educ. Rev. 2012, 29, 134-147.

14. Pensabe-Rodriguez, A.; Lopez-Dominguez, E.; Hernandez-Velazquez, Y.; Dominguez-Isidro, S.; De-la-Calleja, J. Context-aware mobile learning system: Usability assessment based on a field study. Telemat. Inform. 2020, 48, 101346. [CrossRef]

15. Cho, M.-H.; Castañeda, D.A. Motivational and affective engagement in learning Spanish with a mobile application. System 2019, 81, 90-99. [CrossRef]

16. Diacopoulos, M.M.; Crompton, H. A systematic review of mobile learning in social studies. Comput. Educ. 2020, 154, 103911. [CrossRef]

17. Papadakis, S.; Vaiopoulou, J.; Kalogiannakis, M.; Stamovlasis, D. Developing and Exploring an evaluation tool for educational Apps (ETEA) targeting kindergarten children. Sustainability 2020, 12, 4201. [CrossRef]

18. Zafar, S.; Jangsher, S.; Bouachir, O.; Aloqaily, M.; Ben Othman, J. QoS enhancement with deep learning-based interference prediction in mobile IoT. Comput. Commun. 2019, 148, 86-97. [CrossRef]

19. Briz-Ponce, L.; Pereira, A.; Carvalho, L.; Juanes-Méndez, J.A.; García-Peñalvo, F.J. Learning with mobile technologies-Students' behavior. Comput. Hum. Behav. 2017, 72, 612-620. [CrossRef] 
20. Huizenga, J.; Admiraal, W.; Ten Dam, G.; Voogt, J. Mobile game-based learning in secondary education: Students' immersion, game activities, team performance and learning outcomes. Comput. Hum. Behav. 2019, 99, 137-143. [CrossRef]

21. Troussas, C.; Krouska, A.; Sgouropoulou, C. Collaboration and fuzzy-modeled personalization for mobile game-based learning in higher education. Comput. Educ. 2020, 144, 103698. [CrossRef]

22. Kalogiannakis, M.; Papadakis, S. Combining mobile technologies in environmental education: A Greek case study. Int. J. Mob. Learn. Organ. 2017, 11, 108-130. [CrossRef]

23. Kutluk, F.A.; Gülmez, M. A Research about mobile learning perspectives of university students who have accounting lessons. Procedia Soc. Behav. Sci. 2014, 116, 291-297. [CrossRef]

24. Vinu, P.V.; Sherimon, P.C.; Krishnan, R. Towards pervasive mobile learning-The vision of 21st century. Procedia Soc. Behav. Sci. 2011, 15, 3067-3073. [CrossRef]

25. Chen, M.-P.; Wang, L.-C.; Zou, D.; Lin, S.-Y.; Xie, H. Effects of caption and gender on junior high students' EFL learning from iMap-enhanced contextualized learning. Comput. Educ. 2019, 140, 103602. [CrossRef]

26. Deerfield, A. Quantile regression analysis of cooperative learning effects. Int. Rev. Econ. Educ. 2019, 30, 100132. [CrossRef]

27. Johnson, D.W.; Johnson, R.T.; Holubec, E.J. Nuts \& Bolts of Cooperative Learning, 2nd ed.; Interaction Book Co.: Minneapolis, MN, USA, 2007.

28. Huang, M.-Y.; Tu, H.-Y.; Wang, W.-Y.; Chen, J.-F.; Yu, Y.-T.; Chou, C.-C. Effects of cooperative learning and concept mapping intervention on critical thinking and basketball skills in elementary school. Think. Ski. Creat. 2017, 23, 207-216. [CrossRef]

29. López-Mondéjar, L.M.; Pastor, L.M.T. Development of socio-emotional skills through cooperative learning in a university environment. Procedia Soc. Behav. Sci. 2017, 237, 432-437. [CrossRef]

30. Lee, H.; Parsons, D.; Kwon, G.; Kim, J.; Petrova, K.; Jeong, E.; Ryu, H. Cooperation begins: Encouraging critical thinking skills through cooperative reciprocity using a mobile learning game. Comput. Educ. 2016, 97, 97-115. [CrossRef]

31. Johannessen, E.; Szulewski, A.; Radulovic, N.; White, M.; Braund,H.; Howes, D.; Davies, C. Psychophysiologic measures of cognitive load in physician team leaders during trauma resuscitation. Comput. Hum. Behav. 2020, 106393. [CrossRef]

32. Lee, J.Y.; Donkers, J.; Jarodzka, H.; Sellenraad, G.; van Merriënboer, J.J.G. Different effects of pausing on cognitive load in a medical simulation game. Comput. Hum. Behav. 2020, 110, 106385. [CrossRef]

33. García-Martínez, I.; Fernández-Batanero, J.M.; Cobos Sanchiz, D.; Luque de La Rosa, A. Using mobile devices for improving learning outcomes and teachers' professionalization. Sustainability 2019, 11, 6917. [CrossRef]

34. Zhonggen, Y.; Ying, Z.; Zhichun, Y.; Wentao, C. Student satisfaction, learning outcomes, and cognitive loads with a mobile learning platform. Comput. Assist. Lang. Learn. 2019, 32, 323-341. [CrossRef]

35. Andujar, A.; Salaberri-Ramiro, M.S.; Cruz Martínez, M.S. Integrating flipped foreign language learning through mobile devices: Technology acceptance and flipped learning experience. Sustainability 2020, 12, 1110. [CrossRef]

36. Guillén-Gámez, F.D.; Higueras-Rodríguez, L.; Medina-García, M. Developing a regression model of cooperative learning methodology in pre-service teacher education: A sustainable path for transition to teaching profession. Sustainability 2020, 12, 2215. [CrossRef]

37. Hortigüela Alcalá, D.; Hernando Garijo, A.; Pérez-Pueyo, Á.; Fernández-Río, J. Cooperative learning and students' motivation, social interactions and attitudes: Perspectives from two different educational stages. Sustainability 2019, 11, 7005. [CrossRef]

(C) 2020 by the authors. Licensee MDPI, Basel, Switzerland. This article is an open access article distributed under the terms and conditions of the Creative Commons Attribution (CC BY) license (http://creativecommons.org/licenses/by/4.0/). 